\title{
HIGH FLOW NASAL CANNULA THERAPY IS EFFECTIVE FOR POSTEXTUBATION CARE IN EXTREME PREMATURITY, AND IS ASSOCIATED WITH BETTER FEEDING TOLERANCE
}

D. Hariharan 1 , V. Kannappan ${ }^{1}$, S. Panguluru ${ }^{1}$, G. Veluswami¹.

Sooriya Hospital, Neonatology, Chennai, India.

\section{Background and Aims}

High Flow Nasal Cannula therapy (HFNC) is effective as postextubation support in neonates and has advantages over continuous positive airway pressure (CPAP): ease of use, comfort, lower cost. However, studies on HFNC are mainly restricted to infants $>28$ weeks gestation. We studied the effects of HFNC as postextubation support in extreme prematurity

\section{Method}

During the 1-year study period, 87 infants $<28$ weeks gestation who were treated with surfactant and ventilation for RDS were randomly assigned to receive postextubation HFNC at 5-81/min or CPAP 7-8cm $\mathrm{H} 2 \mathrm{O}$. Extubation criteria, PDA treatment, caffeine use and feeding protocols were clearly defined and similar in the 2 groups. Due to limited resources, oral feeds are started at weight $1 \mathrm{~kg}$ in our NICU using paladai (beaked cup). The 2 groups were primarily compared for treatment failure: need for reintubation within 72 hours of extubation (by prespecified blood gas and clinical criteria). Secondary outcomes compared were duration of respiratory support, time to full oral feeds and patient comfort by premature infant pain profile (PIPP) scores.

\section{Results}

\begin{tabular}{|l|l|l|}
\hline & HFNC $(\mathrm{n}=42)$ & CPAP $(\mathrm{n}=45)$ \\
\hline $\begin{array}{l}\text { Mean BW }(\mathrm{g}) \text {, gestation (weeks) } \\
870+54,26.4\end{array}$ & $904+63,26.8$ \\
\hline $\begin{array}{l}\text { Treatment failure } \\
\text { Mean duration of O2 therapy } \\
\text { (days) }\end{array}$ & $7+2.3$ & $29+4.5$ \\
\hline $\begin{array}{l}\text { Mean time to full oral feeds } \\
\text { (days) }\end{array}$ & $41+4.6^{*}$ \\
\hline $\begin{array}{l}\text { Starting Kangaroo mother care } \\
\text { (days) }\end{array}$ & $19.5+2.1$ & $7.4 .3^{*}$ \\
\hline Mean PIPP score $\quad 4.8+2.6$ & 1 \\
\hline Deaths & 2 & $7.8 .4^{*}$ \\
\hline
\end{tabular}

${ }^{*} p<0.05$

\section{Conclusion}

HFNC is safe and effective as postextubation therapy in extreme prematurity. Benefits of HFNC over CPAP include greater infant comfort, easier access for skin-to-skin care and faster development of feeding skills 